\title{
Antibiotic Susceptibility Trends in Blood Culture Isolates over a Period of One Year in a Tertiary Care Center: Hospital Based Study
}

\author{
Surinder Kumar*, Kirti Nirmal, Sanjeev R. Saigal and Indu Bala Garg \\ ${ }^{1}$ Department of Microbiology, Maulana Azad Medical College and Associated Hospitals \\ New Delhi, India \\ ${ }^{2}$ Department of Microbiology, Dr Ram Manohar Lohia Hospital \& Atal Bihari Vajpayee \\ Institute of Medical sciences, New Delhi, India \\ ${ }^{3}$ Department of Microbiology, Laxmi Bai Institute of Dental Sciences, Patiala, Punjab, India \\ *Corresponding author
}

Septicemia remains a serious cause of morbidity and mortality in critically ill patients worldwide. Dealing with severe blood stream infections (BSI) is one of the intractable conditions in hospitals. The empirical treatment given remains pertinent in determining patient outcome, which becomes evidence based when substantiated by knowledge of susceptibility patterns of prevalent pathogenic organism in the set up. To determine the

\section{Keywords}

Nosocomial infection, Antibiogram, Bloodstream infection

Article Info

\section{Accepted:}

07 January 2021

Available Online:

10 February 2021 etiology and the prevalence of the various bacterial isolates in the patients of septicemia and to detail the antibiotic susceptibility profile. A retrospective study was conducted in a tertiary care hospital over a period of one year between January 2016 to December 2016 in which 3027 patient's adults and children with signs and symptoms of septicemia were studied. Venous blood was collected aseptically and inoculated in brain heart infusion broth. Blood culture bottles were incubated at $37^{\circ} \mathrm{C}$. Blind subcultures were performed after 24,48 hours \& subsequently on the $7^{\text {th }}$ day. The plates were incubated at $37^{\circ} \mathrm{C}$ for 24 hrs. Organisms were identified by standard biochemical methods. Antibiotic susceptibility testing was performed by modified Stokes method. Amongst 3027 patients, 1051 (16.09\%) had positive blood cultures. Gram negative aerobes 469 (45\%) like Acinetobacter spp. 164 (34\%); Klebsiella pneumoniae 135 (28\%), Escherichia 123 (26\%) followed by Salmonella typhi $29(6.1 \%)$. While in gram positive aerobes have most commonly staphylococcus aureus 188 (40\%) followed by Enterococcus spp 20 (4.2\%). Acinetobacter spp. and Escherichia coli showed decreased sensitivity to cephalosporin (30-35\%) whereas Klebsiella pneumoniae showed alarmingly low sensitivity to all groups of antibiotics. Within 188 (40\%) Staphylococcus aureus isolates, 61 (32\%) were Methicillin Resistant Staphylococcus aureus (MRSA) but sensitive to vancomycin and linezolid. Streptococcus pneumoniae exhibited $89 \%$ of sensitivity to penicillin G. The study highlights an increasing trend in drug resistance in bacterial isolates from blood. Routine surveillance of antimicrobial susceptibility is warranted to formulate antibiotic policies according to local antibiogram. 


\section{Introduction}

Despite many advances in patient care, blood stream infection (BSI) remains important causes of morbidity and mortality in hospitals especially in developing countries like India. ${ }^{(1)}$ Among the other healthcare associated infections, which mainly include urinary tract infections, surgical site infections and lung infections, BSI constitute for about $14 \%$ and are one of the leading cause of death globally. ${ }^{(2)}$ The occurrence of these infections, their epidemiology, and the invading pathogens have altered in parallel with the evolution in medical care, particularly with emergence of increasing ill and immunocompromised population of hospitalized patients who are often heavily reliant on medical support and indwelling devices. ${ }^{(3)}$ The direct and indirect costs that are affected principally include increased hospital stay, drug treatment, medical, and surgical procedures as well as patients lost salary and illness. ${ }^{(4)}$ Where an early, diagnosis and administration of accurate antibiotics based on patients blood culture report is the ideal approach of managing BSI, the empirical treatment given remains pertinent in determining patient outcome. The increasing antimicrobial resistance among pathogenic bacteria causing BSI has been reported in many studies conducted in India, and is of major concern. ${ }^{(5,6)}$ Antimicrobial resistance is a biological phenomenon acquired by microbes in response to the selective pressure of antimicrobial agents. ${ }^{(7)}$ Numerous surveys regarding bloodstream infections have been conducted in hospitals in developed countries but there appears to be paucity of data from developing countries. $^{(8)}$ The choice of empirical antimicrobial requires the knowledge of the epidemiology of common pathogens in the given setting, which constantly changes, necessitating periodic review. The cock-tail of antimicrobial, which the patients is put on, for empirically managing severely ill patients such as those having BSI, further escalates the development of drug resistance, which can be reduced if the empirical treatment is made evidence based by substantiating it with the knowledge of prevalent pathogenic organisms and their antibiogram.

The present study was conducted to study the etiology, antibiotic susceptibility patterns of bacterial isolatesinpatients admitted with community acquired septicemia and those who developed nosocomial septicemia during their stay in Lok Nayak Jai Prakash Hospital and Maulana Azad Medical College, New Delhi, India.

\section{Materials and Methods}

\section{Study site and population}

This retrospective study was conducted at Lok Nayak Jai Prakash Hospital and Maulana Azad Medical College, New Delhi and it included patients admitted in wards and emergency of tertiary care hospital between the periods of January 2016 to December 2016. Blood culture positive patients were enrolled in this study.

\section{Blood culture}

Venous blood, $5 \mathrm{ml}$ from adults and $3 \mathrm{ml}$ from children was obtained aseptically; $5 \mathrm{ml}$ aliquot inoculated into a medically flat bottle containing $50 \mathrm{ml}$ of brain heart infusion broth and $3 \mathrm{ml}$ blood inoculated in $30 \mathrm{ml}$ brain heart infusion broth in pediatrics population.

Blood cultures were vented and incubated at $37^{\circ} \mathrm{C}$. Blind subculture on to fresh $5 \%$ sheep blood agar and Mac-Conkey agar was performed after 24 hours, $48 \mathrm{hrs}$ and subsequently on the $7^{\text {th }}$ day. The plates were incubated at $37^{\circ} \mathrm{C}$ in air for 24 hours in an atmosphere of $5 \% \mathrm{CO}_{2}$ for $48 \mathrm{hrs}$. Organisms 
were identified by standard biochemical methods. $^{2}$ Staphylococcus isolates were divided by tube coagulase test into staphylococcus aureus (positive) and coagulase negative staphylococcus (negative) strains.

\section{Antibiotic susceptibility testing}

Sensitivity to antibiotics was determined by the modified Stokes method using the commercially available antibiotic discs from Hi Media (Mumbai), Gram negative bacteria were tested with disks containing amoxicillin $(10 \mu \mathrm{g})$, gentamicin $(10 \mu \mathrm{g})$, cefotaxime $(10$ $\mu \mathrm{g})$, netilmicin $(10 \mu \mathrm{g})$, cephalexin $(30 \mu \mathrm{g})$ and ciprofloxacin $(10 \mathrm{mg})$. Salmonella typhi (S.Typhi) and S. paratyphi were also tested with chloramphenicol $(30 \mu \mathrm{g})$. Pseudomonas aeruginosa $(P$. aeruginosa $)$ isolates were further tested with ceftazidime $(10 \mu \mathrm{g})$, piperacillin $(30 \mu \mathrm{g})$ and amikacin (30 $\mu \mathrm{g})$.Gram positive cocci were tested with penicillin (10 units), erythromycin $(5 \mu \mathrm{g})$, amikacin $(30 \mu \mathrm{g})$, gentamicin $(10 \mu \mathrm{g})$, netilmicin $(10 \mu \mathrm{g})$, cefotaxime $(10 \mu \mathrm{g})$ and ciprofloxacin $(10 \mu \mathrm{g})$. Streptococcus pneumonia (S. pneumoniae) strains were tested with $0.25 \mathrm{IU}$ of penicillin disc and all resistant strains were further confirmed by using $1 \mathrm{mg}$ oxacillin disc.

\section{Definitions}

An episode of septicemia was defined as a clinically distinct when one or more blood cultures from the same symptomatic patients yielded positive results..$^{(9)}$ The septicemia was considered to have been community acquired if the positive blood culture was obtained within $48 \mathrm{hrs}$ of admission and nosocomial in origin, if the positive blood culture was obtained after 48 hours of admission. ${ }^{(10)}$ Coagulase negative Staphylococci (CONS), diptheroids and Bacillus species were considered contaminants if they were inconsistent with the clinical features and a repeat sample showed no growth of these bacteria.

\section{Statistical analysis}

Data was recorded on a predesigned Performa and responses were coded for entry in the computer. All the entries were doubly checked for any possible keyboard errors. Data analysis was performed SPSS-17.0. Sensitivity, specificity, positive predictive value and negative predictive value with $95 \%$ confidence interval were calculated. Descriptive statistics were shown in terms of proportions; Proportions were compared with the chi square test with Yates correction or Fishers exact test.

\section{Results and Discussion}

In this study, 3027 (46\%) patients were aged $\leq 15$ years and $1027(15.7 \%)$ aged over 60 years. Males outnumbered females (M: $\mathrm{F}=1.7: 1$ ). Blood cultures were positive in $1051(16.09 \%)$ patients; clinically significant isolation in $1153(17.6 \%)$ and contaminants in $178(2.7 \%)$ specimens (Table 1). Within 1051 blood culture isolations, $561(53.3 \%)$ were Gram-negative bacilli (GNB), 237 (22.6\%) Gram- positive cocci (GPC) and 21 (4.4\%) were Candida spp. The most prevalent isolate was Acinetobacter species 164 (34\%), followed by Escherichia coli 123 (26\%), K. pneumoniae 135 (28\%) emerged as next common pathogens followed by Salmonella Typhi in 29 (6\%).

Among Gram-positive cocci, Staphylococci were the most frequent 188 (40\%), followed by Enterococcus faecalis $20(4 \%)$ and $S$. pneumoniae 08(1.7\%) (Figure 1).

In this study 471 (44.7\%) patients had community acquired septicemia and 581 $(55.3 \%)$ patients had hospital acquired 
septicemia. In our study, Pseudomonas aeruginosa Citrobacter freundii, Staphylococcus aureus and Coagulase negative staphylococcus (CONS) were more frequently isolated in hospital acquired septicemia than in community acquired septicemia and this association was statistically significant $(P=0.035, P=0.028$, $P=0.032$ and $P=0.002$ respectively) (Table 2).

\section{Antibiotic susceptibility pattern in gram negative bacilli}

Penicillin's and cephalosporins: Amongst Pseudomonas aeruginosa isolates, 61 (61.3\%) were sensitive to ceftazidime and $76(76 \%)$ to piperacillin with tazobactam. Acinetobacter spp. and Escherichia coli showed decreased sensitivity to cephalosporin (30-35\%) where as $K$. pneumoniae showed alarmingly low sensitivity to all antibiotics (Table 3).

Aminoglycosides: A total of $80(65 \%)$ gram negative bacilli were sensitive to gentamicin and $63(63 \%)$ were sensitive to netilmicin among which $K$. pneumoniae were again the most resistant.

Ciprofloxacin: Sensitive to ciprofloxacin was documented in 124 (56\%) strains, 178 (32\%) Pseudomonas aeruginosa strains susceptibility to amoxicillin and cotrimoxazole.

Antibiotic resistance among Salmonella typhi: Twenty seven isolates (95\%) sensitive to chloramphenicol; $22(78 \%)$ sensitive to ciprofloxacin and 16 (5.6\%) cefotaxime.

Antibiotic sensitive pattern among Staphylococci: In all $121(61 \%)$ isolates were MRSA; all sensitive to vancomycin and linezolid but resistant to penicillin. Least resistance was depicted against amoxicillin, vancomycin and linezolid.
Antibiotic sensitive among Enterococci spp: $80(67 \%)$ were sensitive to macrolides (erythromycin); $15(18.7 \%)$ sensitive to vancomycin. All isolates were susceptible to linezolid.

Antibiotic sensitive among Streptococcus pneumoniae: seven $(18.9 \%)$ strains were sensitive to penicillin $G$; all isolates were sensitive to vancomycin and linezolid (Table $4)$.

Of the staphylococcal isolates, $61(32 \%)$ were MRSA with none of the isolates being vancomycin resistant $S$. aureus (VRSA) or vancomycin intermediate Staphylococcus aureus (VISA) $28 \%$ of coagulase negative $S$. aureus (CONS) were methicillin-resistant coagulase negative staphylococci (MRCONS).

There was statistical significant association noticed in penicillin antibiotic between MRSA and MSSA (P 0.000, chi-square test). MRSA were isolated in a significantly higher $86(82 \%)$ IPD than $2(1.9 \%)$ OPD patients and this was statistically significant (P 0.000 , chisquare test) (Table 5).

Blood stream infection (BSI) is an important cause of morbidity and mortality in hospitalized patients. Many studies have been undertaken to determine the organism responsible for sepsis all over the world. It varies in different centers and different part of world. Many factors like socio-economic, geographic, use of ventilators, co-morbidity of patient Though the clinical feature may be useful to identify the causes of the blood stream infections, the culture method is the gold standard technique for identifying the causative organisms and for establishing their antibiotic profiles. and self-prescribed antibiotics etc. play a very important role in explaining this difference. ${ }^{(8)}$ 
Table.1 Spectrum of microorganisms isolated from blood cultures $(n=1051)$

\begin{tabular}{|c|c|c|c|c|}
\hline Gram negative aerobes & $\begin{array}{c}\text { Children } \\
\mathrm{n}=417 \\
\mathrm{~S}(\%)\end{array}$ & $\begin{array}{c}\text { Adults } \\
\mathrm{n}=114 \\
\mathrm{~S}(\%)\end{array}$ & $\begin{array}{c}\text { Unknown } \\
\text { Gender } \\
\text { n=30 S }(\%)\end{array}$ & $\begin{array}{c}\text { Total } \\
n=561 \\
S(\%)\end{array}$ \\
\hline Acinetobacter spp. & $118(28 \%)$ & $33(28.9 \%)$ & $13(43 \%)$ & $164(34 \%)$ \\
\hline Klebsiella pneumoniae & $103(24 \%)$ & $28(24.5 \%)$ & $04(13 \%)$ & $135(28 \%)$ \\
\hline Escherichia coli & $85(20.3 \%)$ & $31(27.1 \%)$ & $07(23 \%)$ & $123(26 \%)$ \\
\hline Pseudomonas aeruginosa & $81(19.4 \%)$ & $17(14.9 \%)$ & $03(10 \%)$ & $101(21 \%)$ \\
\hline Salmonella Typhi & $28(6.7 \%)$ & $01(0.8 \%)$ & $\mathbf{0}(\mathbf{0} \%)$ & $29(6.1 \%)$ \\
\hline Proteus mirabilis & $04(0.9 \%)$ & $02(1.7 \%)$ & $02(6.7 \%)$ & $08(1.7 \%)$ \\
\hline Enterobacter spp & $02(0.4 \%)$ & $01(0.8 \%)$ & $01(3.4 \%)$ & $04(0.8 \%)$ \\
\hline Citrobacter freundii & $04(0.9 \%)$ & $01(0.8 \%)$ & $\mathbf{0}(\mathbf{0 \%})$ & $05(1.0 \%)$ \\
\hline Gram positive aerobes & $\begin{array}{l}\text { Children } \\
\mathrm{n}=\mathbf{1 8 6}(\%)\end{array}$ & $\begin{array}{c}\text { Adults } \\
n=54(\%)\end{array}$ & $\begin{array}{c}\text { Unknown } \\
n=5(\%)\end{array}$ & $\begin{array}{c}\text { Total } \\
\mathbf{n}=237(\%)\end{array}$ \\
\hline Staphylococcus aureus & $149(35 \%)$ & $35(30 \%)$ & $04(13 \%$ & $188(40 \%)$ \\
\hline Enterococcus faecalis & $14(3.3 \%)$ & $06(5.2 \%)$ & $\mathbf{0}(\mathbf{0} \%)$ & $20(4.2 \%)$ \\
\hline Streptococcus pneumoniae & $08(1.9 \%)$ & $08(7.0 \%)$ & $\mathbf{0}(\mathbf{0} \%)$ & $08(1.7 \%)$ \\
\hline Candida spp. & $15(3.5 \%)$ & $05(4.3 \%)$ & $01(3.3 \%)$ & $21(4.4 \%)$ \\
\hline Total & 711 & 245 & 95 & 1051 \\
\hline
\end{tabular}

Table.2 Causative organism of hospital and community- acquired septicemia

\begin{tabular}{|l|c|c|c|}
\hline Organism & $\begin{array}{c}\text { Community- } \\
\text { acquired } \\
\text { septicemia } \\
\text { n=581 } \\
\text { S (\%) }\end{array}$ & $\begin{array}{c}\text { Hospital } \\
\text { acquired } \\
\text { septicemia } \\
\text { N=470 } \\
\text { S (\%) }\end{array}$ & P value \\
Chi-square \\
test
\end{tabular}

*n: Community acquired septicemia (CAS), N: Hospital acquired septicemia (HAS). $\mathrm{P}<0.05$ significant 
Table.3 Antibiotic susceptibility pattern of gram-negative organisms isolated from blood culture

\begin{tabular}{|c|c|c|c|c|c|}
\hline \multicolumn{6}{|c|}{ Number of susceptible isolates (\%) } \\
\hline $\begin{array}{l}\text { Antibiotics } \\
\text { Discs }\end{array}$ & $\begin{array}{c}\text { Escherichia } \\
\text { coli } \\
\mathrm{n}=356 \\
\mathrm{~S}(\%)\end{array}$ & $\begin{array}{c}\text { Klebsiella } \\
\text { pneumoniae } \\
\text { n= 264 } \\
\text { S }(\%)\end{array}$ & $\begin{array}{c}\text { Salmonella } \\
\text { typhi } \\
\mathrm{n}=74 \\
\mathrm{~S}(\%)\end{array}$ & $\begin{array}{c}\text { Acinetobacter } \\
\text { spp } \\
\mathrm{n}=\mathbf{3 4 3} \\
\mathrm{S}(\%)\end{array}$ & $\begin{array}{c}\text { Pseudomonas } \\
\text { aeruginosa } \\
\text { n=504 } \\
\text { S }(\%)\end{array}$ \\
\hline Amoxicillin & $33(27.6 \%)$ & $6(4.8 \%)$ & $7(26.6 \%)$ & - & - \\
\hline Ceftazidime & - & -- & - & - & $61(61.3 \%)$ \\
\hline Ceftriaxone & $41(34 \%)$ & $34(25.3 \%)$ & $2(100 \%)$ & $26(16 \%)$ & - \\
\hline Cefotaxime & $37(30.8 \%)$ & $31(23.0 \%)$ & $16(5.6 \%)$ & $41(25.3 \%)$ & - \\
\hline Amikacin & $44(36.5 \%)$ & $21(16 \%)$ & - & $31(19.0 \%)$ & $75(75 \%)$ \\
\hline Gentamicin & $80(65.7 \%)$ & $52(39 \%)$ & - & $88(58.2 \%)$ & $71(71.2 \%)$ \\
\hline Netilmicin & - & - & - & - & $63(63.1 \%)$ \\
\hline $\begin{array}{l}\text { Piperacillin } \\
\text { +tazobactam }\end{array}$ & $30(25 \%)$ & $12(9.58 \%)$ & - & $27(17 \%)$ & $76(76 \%)$ \\
\hline Ciprofloxacin & $56(46.2 \%)$ & $53(39.6 \%)$ & $22(78.2 \%)$ & $82(50 \%)$ & $68(68 \%)$ \\
\hline Chloramphenicol & - & - & $27(94.1 \%)$ & - & - \\
\hline Imipenem & $18(1.5 \%)$ & $19(14.5 \%)$ & - & $11(6.9 \%)$ & $50(50 \%)$ \\
\hline Meropenem & $5(4.8 \%)$ & $23(17.1 \%)$ & - & $21(13 \%)$ & $50(50 \%)$ \\
\hline Colistin & $12(100 \%)$ & $13(100 \%)$ & - & $16(100 \%)$ & $101(100 \%)$ \\
\hline
\end{tabular}

Table.4 Antibiotic susceptibility pattern of Gram-positive organisms isolated from blood culture

\begin{tabular}{|c|c|c|c|}
\hline Antibiotics & $\begin{array}{l}\text { Staphylococcus aureus } \\
\qquad \begin{array}{c}\mathrm{n}=\mathbf{5 0 1} \\
\mathrm{S}(\%)\end{array}\end{array}$ & $\begin{array}{c}\text { Enterococcus spp } \\
\mathrm{n}=\mathbf{8 0} \\
\mathrm{S}(\%)\end{array}$ & $\begin{array}{c}\text { Streptococcus pneumoniae } \\
\qquad \begin{array}{c}\mathbf{n}=37 \\
\mathbf{S}(\%)\end{array}\end{array}$ \\
\hline Penicillin G & $\mathbf{0}$ & - & $7(18.9 \%)$ \\
\hline Cefoxitin & $72(14.3 \%)$ & - & - \\
\hline Amoxicillin & $178(35.5 \%)$ & $54(67.5 \%)$ & - \\
\hline Clindamycin & $110(21.9 \%)$ & - & $6(16.2 \%)$ \\
\hline Erythromycin & $50(9.9 \%)$ & $30(37.5 \%)$ & $6(16.2 \%)$ \\
\hline Gentamicin & $122(24.3 \%)$ & $20(25 \%)$ & - \\
\hline Ofloxacin & $69(13.7 \%)$ & - & $6(16.2 \%)$ \\
\hline Vancomycin & $501(100 \%)$ & $15(18.7 \%)$ & $37(100 \%)$ \\
\hline Linezolid & $501(100 \%)$ & $80(100 \%)$ & $37(100 \%)$ \\
\hline
\end{tabular}


Table.5 Comparison of methicillin resistant staphylococcus aureus (MRSA) \& methicillin sensitive staphylococcus aureus (MSSA) blood isolates

\begin{tabular}{|c|c|c|c|}
\hline Category & $\begin{array}{c}{ }^{*} \text { MRSA } \\
\text { n=104 }(\%)\end{array}$ & $\begin{array}{c}\operatorname{MSSA}^{* *} \\
\mathrm{n}=66(\%)\end{array}$ & $\begin{array}{c}\text { P value, } \\
\text { Chi-square test }\end{array}$ \\
\hline Children & $77(74 \%)$ & $52(78 \%)$ & 0.48 \\
\hline Adults & $23(22 \%)$ & $10(15 \%)$ & 0.26 \\
\hline $\begin{array}{l}\text { Location } \\
\text { IPD } \\
\text { OPD } \\
\text { ICU }\end{array}$ & $\begin{array}{c}86(82 \%) \\
2(1.9 \%) \\
13(12.5 \%)\end{array}$ & $\begin{array}{c}53(80 \%) \\
1(1.5 \%) \\
6(9.09 \%)\end{array}$ & $\begin{array}{l}0.00 \\
1.00 \\
0.49\end{array}$ \\
\hline Antibiotics & $\mathrm{N}=$ Sensitivity (\%) & $\mathbf{N}=$ Sensitivity $(\%)$ & \\
\hline Penicillin & $72(0 \%)$ & $\mathbf{0}(\mathbf{0})$ & 0.00 \\
\hline Clindamycin & $101(50.49 \%)$ & $71(71.8 \%)$ & 0.65 \\
\hline Erythromycin & $103(16.5 \%)$ & $46(46.7 \%)$ & 0.32 \\
\hline Vancomycin & $26(100 \%)$ & $16(100 \%)$ & 0.91 \\
\hline Linezolid & $25(100 \%)$ & $17(100 \%)$ & 0.48 \\
\hline Ciprofloxacin & $6(16.6 \%)$ & $2(0 \%)$ & 0.85 \\
\hline Ofloxacin & $92(21.73 \%)$ & $59(64.4 \%)$ & 0.67 \\
\hline Gentamicin & $101(50.49 \%)$ & $63(88.8 \%)$ & 0.52 \\
\hline Amikacin & $102(92.15 \%)$ & $66(100 \%)$ & 0.34 \\
\hline
\end{tabular}

Fig.1 Prevalence of organisms in blood stream infection (BSI)

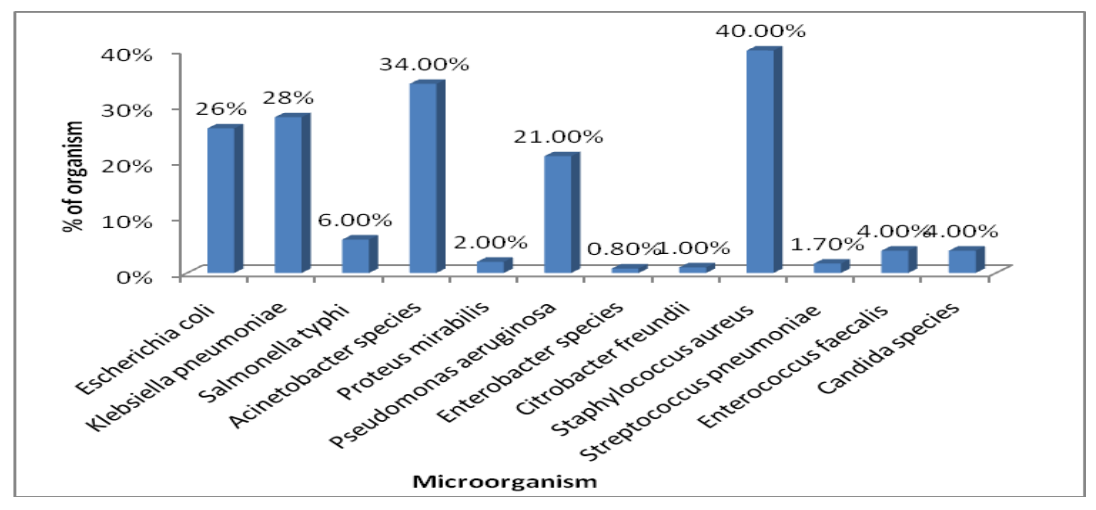

Blood culture positivity rate in our study at $1051(16.01 \%)$ higher than an earlier Indian study which reported $584(6.97 \%)$ isolations (9) A very recent study done in south India also showed $8.39 \%$ culture positive samples ${ }^{(10)}$. Similarly, an Ethiopian study also showed an $8.8 \%$ blood culture positivity rate ${ }^{(11)}$ which may be attributed to the fact that most of our patients would have had a central line, and other associated risk factors which could have be most common cause of BSI. In India, most of the patients are given antibiotics before they come to the tertiary care hospital or they undergo self-medication. In the present study, the highest rate of prevalence of BSI was found in age group 21-40 years 
which coincides with earlier reports. ${ }^{(12)}$ The frequency of isolation of Gram-negative organisms were almost twice $(62.9 \%)$ than Gram-positive isolates $(29.6 \%)$ in our study, higher than $45 \%$ rate for GNB reported in a multicentric European study, (13) which documented an increasing trend of Gramnegative infections but comparable to a recent Indian study. ${ }^{(14,15)}$ Similar results were also seen in a study which was conducted in the western part of Nepal ${ }^{(16)}$ and Kavre ${ }^{(17) .}$

We observed a gradual but definite rise in isolation of Acinetobacter species (19.0\%) and $K$. pneumoniae (16.5\%) in septicemia; Enterobacteriaceae accounting for more than half of the total Gram-negative BSI. Klebsiella spp. (16.5\%) was isolated more often than Escherichia coli $(15 \%)$ which has since long been reported as the commoner cause of septicemia. ${ }^{(18)}$

S.aureus (19.7\%) was the most common gram positive isolate followed by Enterococcus spp. (3.4\%) and Streptococcus pneumonia (2.4\%) whereas CONS (28\%) isolations show drastically increased as compared to previous study (9\%) done in same setting a decade ago. ${ }^{(19)}$ This highlighted a dramatic increase in CONS isolations associated sepsis when compared to other studies. ${ }^{(20,21)}$

Incidence of Enterococcus faecalis too appears to be on the ascendance. Increase in sepsis due to Klebsiella, Acinetobacter, $S$. aureus and Enterococci spp. can be related to the increased incidence of nosocomial infections. Contrary to the expected trend, bacteremia due to Haemophilus influenza and Neisseria meningitides were negligible in our study. This could have been due to prior antibiotic treatment as patients with clinical diagnosis of meningitis are often pre-treated before admission resulting in negative blood cultures.
It is particularly useful for the clinicians to possess susceptibility data on categories of organism rather than for particular organism only. Among the gram-negative bacilli isolated from blood, the lowest resistance levels were observed for carbapenem $(23.3 \%)$ followed by amoxicillin (32\%) and cefotaxime $(28.6 \%)$ although significant resistance were observed with these antibiotics, concordant with the findings of Thacker et al., ${ }^{(9)} K$. pneumoniae and Escherichia coli both exhibited an alarmingly high level of resistance to amoxicillin and cephalosporin and this resistance was reflected among all the other gram negative species also. A similar resistance of E.coli to amoxicillin was reflected in a collaborative European study. ${ }^{(21)}$ Almost $84 \%$ isolates of $K$. pneumoniae and $64 \%$ of E.coli were resistant to the aminoglycosides. This level of resistance is unprecedented and far exceeds the resistance mentioned in other studies. ${ }^{(14,}$ ${ }^{19)} K$. pneumoniae showed highest percentage of drug resistance to all the group of antibiotics tested. This finding is similar to study by Mathur et al., ${ }^{(22)}$ The prevalence of S. typhi in our study $(2.7 \%)$ is in concordance with Duggal et al. ${ }^{(23)}$ Salmonella Typhi displayed zero resistance to ceftriaxone, similar to study by Madhulika et al ${ }^{(23)}$ while, $22 \%$ resistance was observed by ciprofloxacin.

Among the gram-negative bacilli, $P$. aeruginosa, is important nil-fermenters was isolated in $9.6 \%$ of cases consistent with the previous finding in the same setting decade ago were showed $9 \%$ positivity. ${ }^{(20,21)}$ Surprisingly $P$. aeruginosa did not express high resistance levels to any group of antibiotics. Acinetobacter spp. which is an emerging cause of the late onset septicemia was isolated in $15.6 \%$ of the cases, similar to study performed by Arora et al., showing almost nearly equal $14.9 \%$ positivity. ${ }^{(24)}$ 
S. aureus was found to have significant resistance to penicillin (100\%) while all isolates were sensitive to vancomycin and Linezolid. Resistance to erythromycin and Ofloxacin was moderately high (50-60\%). Amongst the aminoglycosides, maximum resistance was demonstrated against gentamicin (35\%) and least to amoxicillin (4.9\%). Similar results have been reported by other study. ${ }^{(21)}$ CONS showed significant resistance to penicillin (74\%) while only $14 \%$ isolates were resistant to aminoglycosides.

Enterococci spp. displayed markedly high level of susceptibility (30-40\%); highest against macrolides $(85 \%)$ and amoxicillin (73\%). concordant with a study conducted in Southern Europe ${ }^{(19)}$ that reported 20-30\% susceptibility. Amongst $\beta$ - lactam antibiotics, the susceptibility noticed in the present study varied from 50-60\%, while earlier reports have mentioned higher levels of susceptibility $(80 \%) .{ }^{(21)}$

S. pneumoniae showed susceptibility to most antimicrobials tested. $88 \%$ resistant to penicillin and $77 \%$ resistant to erythromycin and Clindamycin which was considerably higher than the susceptibility patterned reported in previous studies. ${ }^{(24)}$ These results signify the varying levels of drug susceptibility amongst the gram positive microbes in different regions.

The emergence of Acinetobacter spp. (16.90\%) and Staphylococcus aureus (19.5\%) in significant numbers which, moreover, exhibit considerable antibiotic resistance is a cause for alarm since these bacteria are acquired primarily from hospital than community, pointing to apressing need to bring down incidence of nosocomial infection. Moreover, rational and cautions use of antibiotics is essential for the reduction in antibiotic resistance. Clinical laboratories should be able to detect resistance or reduced susceptibility in time to assist in antimicrobial treatment and also in infection control. A high prevalence of drug resistant organisms emphasizes need for active surveillance cultures, for early planning of infection control measures and guiding on empirical use of antibiotics.

In conclusion as the degree of the antibiotic resistance rate for the blood stream pathogens is alarming, we conclude that Klebsiella pneumoniae and Acinetobacter spp, Staphylococcus aureus and Enterococcus faecalis associated sepsis is increasing. Antibiotic susceptibility patterns underline a marked increase in resistance to $\beta$ - lactam and aminoglycosides group of antibiotics.

\section{References}

1. Sharma R, Sharma CL, Kapoor B. Antimicrobial resistance: Current problems and possible solutions. Indian $\mathrm{J}$ Med Sci, 2005; 59:120-9.

2. Digiovine B, Chenoweth $\mathrm{C}$, Watts $\mathrm{C}$, Higgins $\mathrm{M}$. The attributable mortality and costs of primary nosocomial bloodstream infections in the intensive care unit. Am J Respir. Crit care Med. 1999; 160:976-81.

3. Karchmer AW, Nosocomial bloodstream infections: Organism risk factor and implications. Clin infect Dis 2000; 31 (4): 5139-43.

4. Orsi GB, Di Stefano L, Noah N. Hospital- acquired, and laboratory confirmed bloodstream infections: Increased hospital stay and direct costs. Infect Control Hosp Epidemiol.2002; 23: 190-7.

5. Koutouby A, Habibulleh J.Neonatal sepsis in Dubai, united Atab Emirates. J Trop Pediatr 1995; 41:177-80.

6. Kamat U, Ferreira A, Savio R, Motghare D. Antimicrobial resistance among nosocomial isolates in a teaching hospital in Goa. Indian J Community Med. 2008; 
33: 89-92.

7. Horan TC, Andrus M, Dudeck MA.CDC/ NHSN surveillance definition of health care- associated infections and criteria for specific types of infections in the acute care setting.AM J Infect Control.2008; 36: 309-32.

8. Arora U, Devi P. Bacterial profile of blood stream infections and antibiotics resistance pattern of isolates. J K Sci. 2007; 9: 186-90.

9. Thacker N, Pereira N, Banavali S etal, Epidemiology of blood stream infection in peadiatric patients at a tertiary care cancer centre. Indian J Cancer 2014; 51:438-41.

10. Vanitha RN, Kannan G, Venkata NM, Vishwakanth D, Nagesh VD, Yogitha M, et al., A retrospective study on blood stream infections and antibiotic susceptibility patterns in a tertiary care teaching hospital. Int J Pharm Pharm Sci. 2o12; 4:543-48. (15) Zenebe T, Kannan S, Yilma D, Beyene G. Invasive bacterial pathogens and antibiotic susceptibility patterns in University associated specialized hospital in southeast Ethopia. Ethiop J Health Sci. 2011; 21: 1-8.

11. Ahmed N H, Hussain T. Antimicrobial Susceptibility Patterns of Leading Bacterial Pathogens Isolated from Laboratory Confirmed Blood Stream Infections in a Multi Specialty Sanatorium. Glob Infect Dis. 2014 OctDec; 6(4): 141-146.

12. Mikulska M, Viscoli C, Orasch C et al. Aetiology and resistance in bactereamias among adult and paediatric haematology and cancer patients. J Infect 2014; 68: 321-31.

13. Gupta A, Kapil A, Kabra SK, Lodha R, Sood S, Dhawan B, et al., Prospective study estimating healthcare associated infections in a paediatric hemato-oncology unit of a tertiary care hospital in North India. Indian J Med Res
2013; 138:944-9.

14. Rose W, Veeraraghavan B, Pragasam AK, Verghese VP. Antimicrobial susceptibility profile of isolates from pediatric blood stream infections. Indian Pediatr 2014; 51:752-3.

15. Eykyn SJ. Bacteremia, septicaemia and endocarditis. In: Collier L, Balows A, Sussman M, eds. Topley and Wilson microbiology and microbial infections. $9^{\text {th }}$ ed. London: Arnold, 1998: Vol 3: 277-98.

16. Easow MJ, Joseph MN, Dhungel AB, Chapagain B, Shivananda PG. Blood Stream Infections among febrile patients attending a teaching hospital in Westren Region of Nepal. AMJ. 2010; 3(10): 63337. (12) Sharma NP, Peacock SJ, Phumratanaprapin W, Day N, White N, Pukrittayakamee S. A hospital-based study of bloodstream infections in febrile patients in Dhulikhel Hospital Kathmandu University Teaching Hospital, Nepal. Southeast Asian J Trop Med Public Health. 2006; 37:351-56.

17. Kumar S, Rizvi M, Vidhani S et al. Changing face of septicaemia and increasing drug resistance in blood isolates. Indian J Pathol Microbiol., 2004, vol 47(3): 441-446.

18. Dawodu A, A1 Umran K, TwumDanso k. A case control of neonatal sepsis: Experience from Saudi Arabia. L Trop Pediatr 1997; 43: 84-8.

19. Dombusch K, King A, Legakis N. The European study group on antibiotics resistance. Incidence of antibiotic resistance in blood and urine isolates from hospitalized patients. Report from a European Collaborative study .Scand J Infect Dis 1998; 30: 281-8.

20. Mathur $\mathrm{P}$, Varghese $\mathrm{P}$, Tak $\mathrm{V}$ et al. Epidemology of blood stream infections at a level- 1 trauma care centre of India.J Lab Physician 2014; 6(1):22-27.

21. Duggal S, Rongpharpi SR, Gur R, et al., Etiology and susceptibility of blood 
stream infections in a referral hospital in North Delhi: A one year studt, Research Journal of Pharmaceutical Biological and Chemical Sciences 2014; 5(2): 1859-64. 22. Madhulika U, Harish BN, Parija SC. Current Salmonella typhi isolates in pondichery. Indian J Med Res 2004; 120:111-114.

23. Arora U, Jaitwani J. Acinetobacter spp.
An emerging pathogen in neonatal septiceamia in Amritsar. I ndian J Med Microbiol.2006; 24:81.

24. Brett NS. Emergency of high level cefotaxime resistance in S.pneumonial strains in New Zealand. J Med Microbiol 2001; 50:173-6.

\section{How to cite this article:}

Surinder Kumar, Kirti Nirmal, Sanjeev R. Saigal and Indu Bala Garg. 2021. Antibiotic Susceptibility Trends in Blood Culture Isolates over a Period of One Year in a Tertiary Care Center: Hospital Based Study. Int.J.Curr.Microbiol.App.Sci. 10(02): 428-438. doi: https://doi.org/10.20546/ijcmas.2021.1002.051 